\title{
Hundred Billion Per Liter
}

National Cancer Institute

\section{Source}

National Cancer Institute. Hundred Billion Per Liter. NCI Thesaurus. Code C105488.

A concentration unit expressed as a number or quantity of objects in hundred billions per unit of volume equal to one liter. 